\title{
Decoding in the dark: extracting information from spontaneous activity in primary visual cortex
}

\author{
Iñigo Romero Arandia*, Ruben Moreno-Bote \\ From Twenty First Annual Computational Neuroscience Meeting: CNS*2012 \\ Decatur, GA, USA. 21-26 July 2012
}

Understanding the role of spontaneous activity in cortex is a crucial challenge, since it might be involved in sampling cortical states and in the preparation of the network for rapid responses to external stimuli. However, whether there is also information processing during spontaneous activity is still debated.

We asked how much information it is possible to extract from V1 spontaneous activity following visual stimulation. We analyzed multi-electrode (100) recordings in an experiment setup where a drifting grating with 8 possible motion directions was presented for $1 \mathrm{~s}$ and was followed by a blank period of around 1s. Using maximum likelihood estimation (MLE) on a simple independent Poisson model, we found than spontaneous activity during a blank period allowed us to predict the stimulus orientation previously used with an accuracy of around $25 \%(100 / 8=12.5 \%$ chance level $)$.

This result shows that spontaneous activity has in fact information about the preceding stimulus and establishes an information lower bound. Another crucial question is to know by how much we can improve the information that can be decoded. We observed that spontaneous activity is characterized by periods of high activity interleaving periods of low activity. Surprisingly, the average population vector during high activity periods was almost perfectly a scaled version of the population vector at low activity periods. This suggests a model where neurons are Poisson-like but their rates are modulated by a common mode. Applying this model to the data we could predict correctly $40 \%$ of the stimulus orientations.

Our results not only show that on average approximately half of the information provided during stimulation

Foundation Sant Joan de Deu, Parc Sanitari Sant Joan de Deu, 08950 Esplugues de Llobregat, Barcelona, Spain is still present in the subsequent blank period, but also suggest that global slow oscillations in spontaneous activity -well described by a multiplicative factor akin to the effect of attention to neuronal activity- are a critical component for information processing. Understanding the role of spontaneous activity in cortex is a crucial challenge, since it might be involved in sampling cortical states and in the preparation of the network for rapid responses to external stimuli. However, whether there is also information processing during spontaneous activity is still debated.

Published: 16 July 2012

doi:10.1186/1471-2202-13-S1-P83

Cite this article as: Arandia and Moreno-Bote: Decoding in the dark: extracting information from spontaneous activity in primary visual cortex. BMC Neuroscience 2012 13(Suppl 1):P83.

Submit your next manuscript to BioMed Central and take full advantage of:

- Convenient online submission

- Thorough peer review

- No space constraints or color figure charges

- Immediate publication on acceptance

- Inclusion in PubMed, CAS, Scopus and Google Scholar

- Research which is freely available for redistribution

Submit your manuscript at www.biomedcentral.com/submit
( Biomed Central 